\title{
Post-dural puncture headache following acupotomy using "Wonli-acupuncture needle" - A case report -
}

\section{Hyungtae Kim ${ }^{1}$, Cheol-Hyeong Lee ${ }^{2}$, and Yeon-Dong Kim ${ }^{2,3}$}

Received January 29, 2018

Revised March 12, 2018

${ }^{1}$ Department of Anesthesiology and Pain Medicine, Presbyterian Medical Center, Jeonju, ${ }^{2}$ Department of Anesthesiology and Pain Medicine, ${ }^{3}$ Wonkwang Institute of Science, Wonkwang University College of Medicine, Iksan, Korea

\author{
Corresponding author \\ Yeon-Dong Kim, M.D., Ph.D. \\ Department of Anesthesiology and \\ Pain Medicine, Wonkwang University \\ College of Medicine, 895 Muwang- \\ ro, Iksan 54538, Korea \\ Tel: 82-63-859-1562 \\ Fax: 82-63-857-5472 \\ E-mail: kydpain@hanmail.net \\ ORCID \\ http://orcid.org/0000-0003-0404-2657
}

Acupuncture is a popular technique used worldwide, particularly for clinical pain management. Diverse methods of acupuncture with several types of needle have recently been introduced; however, medical evidence of the treatment and safety of many of these techniques has not been established. In addition, severe, life-threatening acupuncture-related complications have been reported even though the treatment is considered to be safe. We report a case of a post-dural puncture headache that occurred following acupuncture for the treatment of lower back pain, with a literature review. Pain physicians should consider that acupuncture can cause far more serious side effects than those previously known.

Key Words: Acupuncture, Post-dural puncture headache, Postoperative complications.

Lower back pain (LBP) is one of the most common painrelated complaints that lead patients to seek medical care [1]. Underlying disc herniation and subsequent radicular symptoms from direct compression of nerve roots or inflammatory mediators related to disc disruption are frequent causes of the pain, leading to these consultations. Various treatments for these lumbar diseases have been introduced. Acupuncture has also been studied as an alternative treatment modality, with worldwide application, particularly in clinical pain management. Acupuncture has been recognized as relatively safe for patients, especially in East Asia, and many patients with LBP are treated with acupuncture in clinical practice.

Spine surgery has limited effects for the management of LBP [2], so the need for non-operative therapies such as pharmacological therapy, physical therapy, and manipulation has increased, but these methods do not have satisfactory therapeutic effects and are not commonly used [3]. Acupuncture was introduced as a way to remove attached tissues, reduce pressure on the nerve, and improve the circulation of the surrounding area in cases of lumbar spinal stenosis or lumbar disc herniation. New acupuncture treatments for these diseases are also being tried [4].

However, the effects of acupuncture are still controversial, and the principles of treatment are unclear. Although many studies have evaluated the effects of acupuncture in the management of LBP, few have evaluated the side effects of acupuncture-related procedures [5].

Here, we report a case of dural puncture headache due to acupotomy, a recently introduced long-needle acupuncture technique in the oriental medicine, and discuss the principles of acupuncture treatment necessary to provide useful information for pain physicians. The authors received written permission from the patient to report and provide details about this case.

This is an Open Access article distributed under the terms of the Creative Commons Attribution Non-Commercial License (http://creativecommons.org/licenses/by-nc/4.0) which permits unrestricted non-commercial use, distribution, and reproduction in any medium, provided the original work is properly cited. 

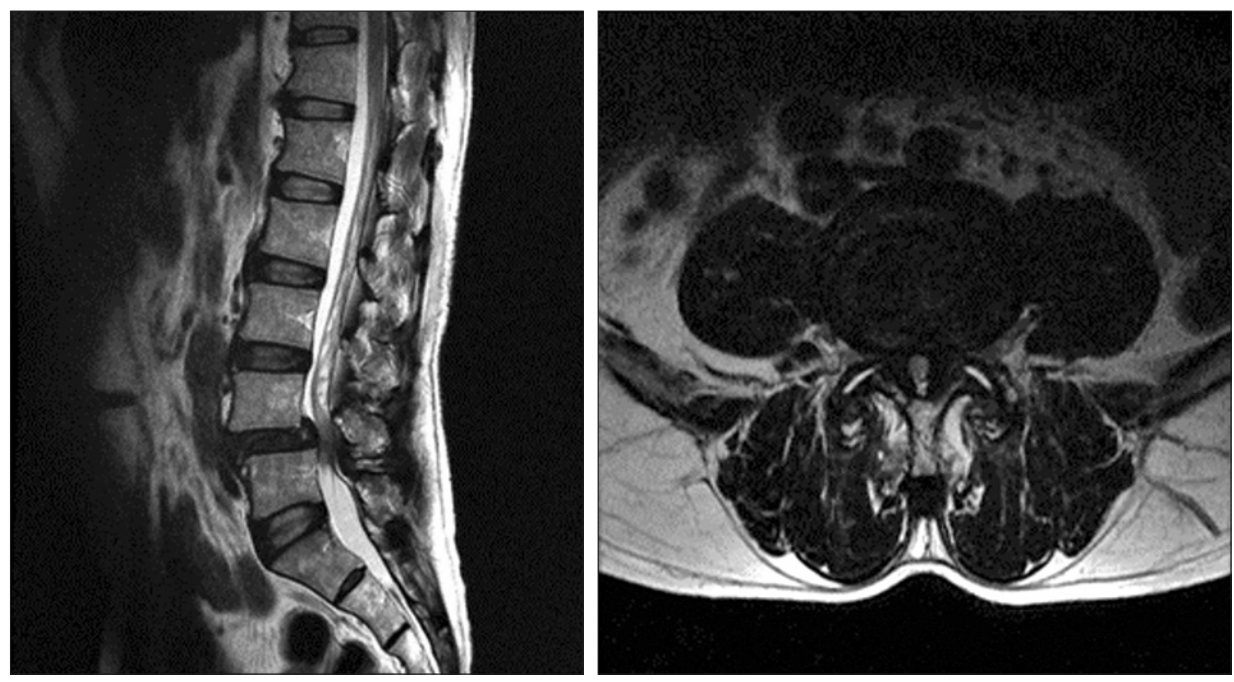

Fig. 1. Magnetic resonance imaging of the lumbar spine.

\section{CASE REPORT}

A 67-year-old man (height: $169 \mathrm{~cm}$, weight: $65 \mathrm{~kg}$ ) was admitted to our hospital from the emergency department. The patient had had a severe headache for 3 days, along with high blood pressure (systolic: $180 \mathrm{mmHg}$, diastolic: $100 \mathrm{mmHg}$ ), that had begun 24 hours following acupuncture treatment. His headache was accompanied by nausea and vomiting; was located in the frontal region of the head, manifesting as a severe dull headache; and his symptoms seemed to decrease in the supine position.

He had no particular medical history other than LBP and had undergone prostate surgery five years previously. The patient had received acupuncture treatment in the oriental hospital for two consecutive days, four days prior to his hospital visit; his headache had begun the following morning approximately 12 hours after the last acupuncture procedure. He took acetaminophen for symptom relief before he came to the hospital, but it was not effective.

The patient had received acupotomy with 4 kinds of specially manufactured long needles called Wonli-acupuncture needles after a diagnosis of lumbar foraminal stenosis with spondylolisthesis on lumbar magnetic resonance imaging (MRI) (Fig. 1). The procedure was performed by the physician of oriental medicine in the lumbar region, without image guidance, under light sedation which was in effect for approximately 1 hour (Fig. 2). In the emergency room, the results of a neurological examination and brain computer tomography were unremarkable, but as the symptoms did not

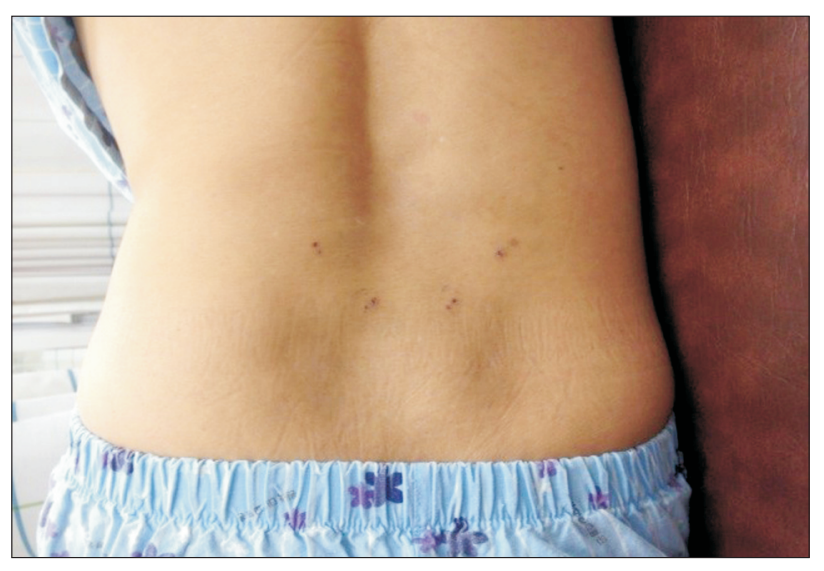

Fig. 2. Skin site of needle entry in acupotomy.

resolve, the patient was hospitalized for further evaluation. MR myelography was conducted to determine the presence of a cerebrospinal fluid (CSF) leakage. It showed fluid collection around the lumbar foramen at the levels of L4 and L5, which was indicative of CSF leakage (Fig. 3). The brain MRI images showed curvilinear dural hyperintensity and very small subacute fluid collection along both cerebral convexity and diffuse dural enhancement, suggesting intracranial hypotension followed by a dural puncture (Fig. 4).

On the basis of the diagnosis of post-dural puncture headache, we performed autologous blood patches twice with a 5-day interval (first, $25 \mathrm{ml}$; second, $20 \mathrm{ml}$; interlaminar approach). After 14 days of conservative treatment, the patient was discharged without any specific symptoms or neurologic complications. There was no symptom recurrence by the second or sixth week of follow-up. The symptoms were then 

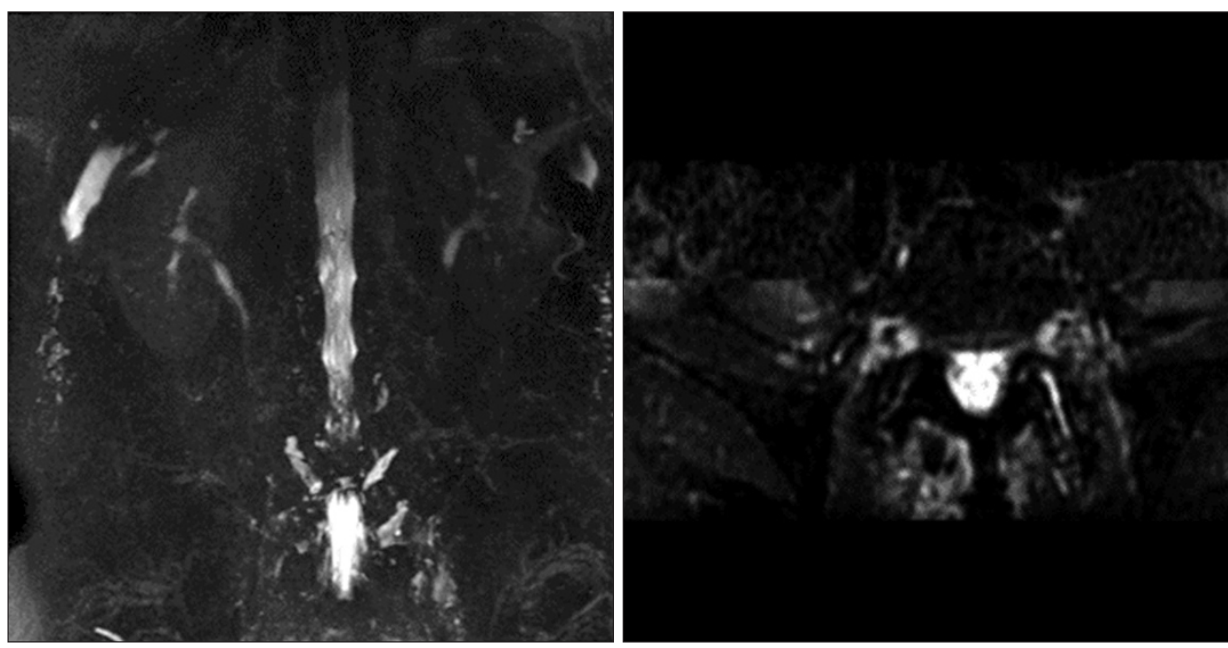

Fig. 3. Magnetic resonance myelography showing cerebrospinal fluid leakage in the lumbar spine.

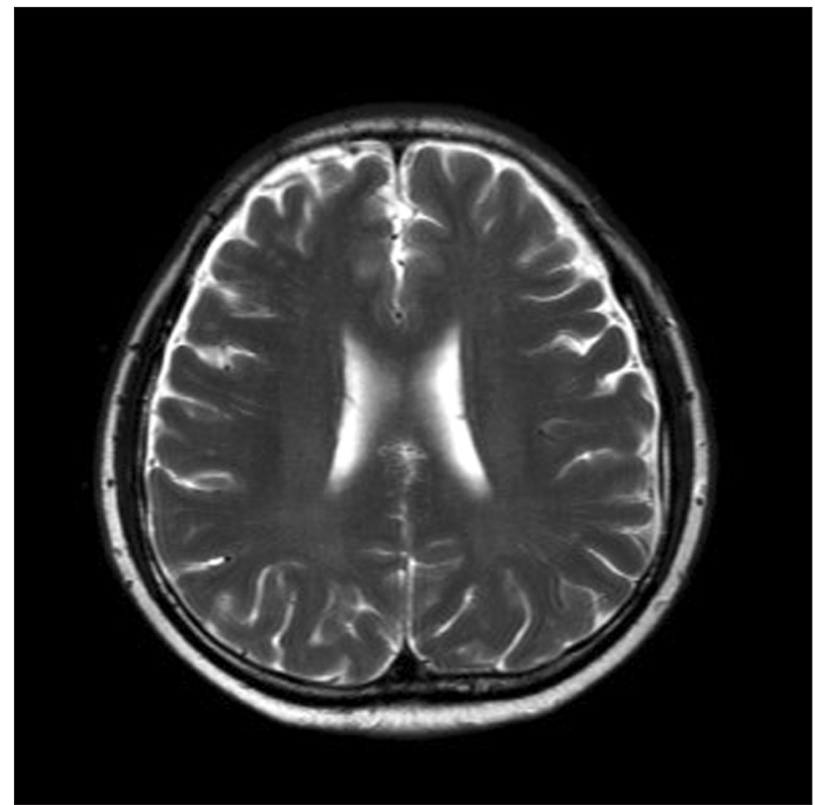

Fig. 4. Brain magnetic resonance imaging.

considered to be completely resolved.

\section{DISCUSSION}

Acupuncture is a treatment commonly used in oriental medicine and generally involves directly inserting 15 to 125-mm-long acupuncture needles with various gauges into symptomatic areas in the back, buttocks, and legs [6].

As the interest and research in oriental medicine have increased in recent decades, the use of acupuncture in East Asia and the rest of the world has also increased. In oriental medicine, acupotomy was introduced as a new treatment method to remove chronic and incorrigible lesions by dissecting, peeling, or cutting soft tissue adhesions using acupuncture needles specifically manufactured for that purpose with thick needle body and its end resembling a sharp knife [7].

It has been used for the management of LBP, but there are only a few articles showing its clinical effects. An advantage is that it is considered to be a relatively simple procedure that takes approximately 10 to 15 minutes to complete. It is also easy to perform, and recovery is rapid, so it is possible to return to daily life immediately after the procedure [8]. However, even there was a report of a case related dura puncture, procedural information and reviews on complications are quiet limited [9]. As there were always risk of injury such as nerve, vessels and other critical structure due to its sharp end during acupotomy, recently a new needle having round tip with more curvature than original tools of acupotomy has been introduced called "Wonli-acupuncture needle" as used in our case [10].

Lee et al. [10] introduced this needle, having 4 types with 1 to $2 \mathrm{~mm}$ in diameter and 105 to 255 in length with round tips (Fig. 5A). In their report, their target point were the zygapophyseal joint and intervertebral foramen (Fig. 5B). An incision is made at that points in/out/up/down from the articular process along the bony surface. Soft tissue and yellow ligament are considered to be removed at the physician's discretion.

There are some crucial pitfalls that necessitate caution to be reviewed through our case. The procedure this patient underwent was performed without imaging guidance, and technique of sedation was used. Sedation analgesia is known 

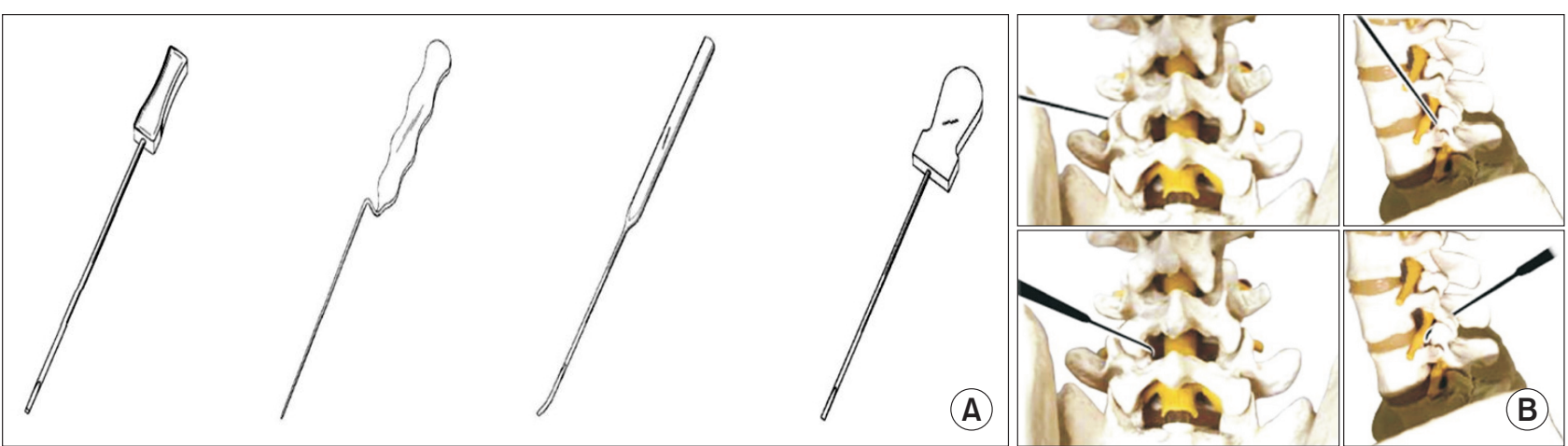

Fig. 5. (A) Types of needle and (B) target points of acupotomy.

to induce various levels of relief from anxiety, stress, and discomfort and to provide compassionate patient care during painful therapeutic interventions [11].

However, when performing acupotomy in the lumbar region of the spine using a blind technique, there is a very high risk of direct needle injury to the spinal cord or a tear of the dura within the intervertebral foramen which can occur more frequently with inexperience practitioners. Needle contact with the spinal cord is likely to elicit strong paresthesia, and sedation may block the patient's perception of needleinduced paresthesia, increasing the likelihood of accidental perineural injury or a dural tear when the need tips are deeply inserted. The physician cannot ensure the exact position of the acupuncture needle tip; the understanding depends on sensory feedback from the hands. Spinal stenosis and spondylolisthesis are more dangerous circumstances as they are associated with the anatomical changes. Even with the exact needle position, there is no objective evidence that it successfully removed tissue of adhesion other than feeling of physician's hand.

Additionally, $12.3 \%$ of patients who received acupotomy reported a headache after the procedure [12].

This relative high percentage of post-acupotomy headaches is a serious problem that cannot be ignored, as the effectiveness of the procedure has not been correctly evaluated. Acupotomy should be used only in cases in which the risk is believed to be outweighed by the benefit. Although, acupotomy is considered most likely to benefit patients with back pain and neck pain, there is an enormous demand for evidence-based review to explore the integration of acupuncture into acute and chronic pain management, all the more used with new needle. Derry et al. [6] performed a systematic review and concluded that effectiveness was often overstated by including studies that were likely to be biased, which may distort the clinical evidence.

Other reported complications associated with acupuncture must be considered, such as hemorrhage, acute infection, disease transmission, and direct injury to internal organs or neural tissue $[13,14]$. These complications are especially common in cases performed without image guidance, as in the case described here.

In conclusion, to our knowledge, this is the first case of post-dural puncture headache following acupotomy, with a detailed explanation of the acupotomy procedure. With increasing advances in acupuncture-related techniques for the management of LBP, pain physicians should also consider other related complications. The possibility of an iatrogenic post-dural puncture headache should be evaluated in any case of a severe headache following acupotomy. Evidence of adverse events can be used to improve the safety of acupuncture, and is required for a more systemic evaluation of the effects of acupotomy.

\section{ACKNOWLEDGMENTS}

This work was supported by Wonkwang University 2017.

\section{REFERENCES}

1. Kim YD, Moon HS. Review of medical dispute cases in the pain management in Korea: a medical malpractice liability insurance database study. Korean J Pain 2015; 28: 254-64.

2. Weinstein JN, Tosteson TD, Lurie JD, Tosteson AN, Blood E, Hanscom B, et al. Surgical versus nonsurgical therapy for lumbar 
spinal stenosis. N Engl J Med 2008; 358: 794-810.

3. Kreiner DS, Shaffer WO, Baisden JL, Gilbert TJ, Summers JT, Toton JF, et al. An evidence-based clinical guideline for the diagnosis and treatment of degenerative lumbar spinal stenosis (update). Spine J 2013; 13: 734-43.

4. Kim HS, Kim SY, Kim HJ, Kim ES, Kim YI. The effect of acupotomy on lumbar herniated intervertebral disc: report of a case series. Acupuncture 2015; 32: 185-95.

5. Lao L, Hamilton GR, Fu J, Berman BM. Is acupuncture safe? A systematic review of case reports. Altern Ther Health Med 2003; 9: 72-83.

6. Derry CJ, Derry S, McQuay HJ, Moore RA. Systematic review of systematic reviews of acupuncture published 1996-2005. Clin Med (Lond) 2006; 6: 381-6.

7. Shui F, Lingyun G, Hongbo Z. Lumbar spinal stenosis clinical acupotomy therapy. Mod J Chinese Med 2009; 18: 1389-90.

8. Yuk DI, Kim KM, Jeon JH, Kim YI, Kim JH. A review of trends for acupotomy. Acupuncture 2014; 31: 35-43.

9. Jo DJ, Lee BJ, Sung JK, Yi JW. Development of postdural puncture headache following therapeutic acupuncture using a long acupuncture needle. J Korean Neurosurg Soc 2010; 47: 140-2.

10. Lee GM, Lee EY, Han JH, Cho KH, Kang SR, Yoon SH. Effects of Wonli acupuncture procedure in patients with LSS: a clinical, retrospective study. Evid Based Complement Alternat Med 2014; 2014: 212098.

11. Manchikanti L, Damron KS, Rivera JJ, McManus CD, Jackson SD, Barnhill RC, et al. Evaluation of the effect of sedation as a confounding factor in the diagnostic validity of lumbar facet joint pain: a prospective, randomized, double-blind, placebocontrolled evaluation. Pain Physician 2004; 7: 411-7.

12. Ko MK, Kim JH, Hong KE. The study on post acupotomy headache. J Korean Acupunct Moxib Soc 2010; 27: 89-95.

13. Windsor RE, Storm S, Sugar R. Prevention and management of complications resulting from common spinal injections. Pain Physician 2003; 6: 473-83.

14. Domenicucci M, Marruzzo D, Pesce A, Raco A, Missori P. Acute spinal epidural hematoma after acupuncture: personal case and literature review. World Neurosurg 2017; 102: 695.e11-4. 